\title{
ANALECTA HUSSERLIANA
}

THE YEARBOOK OF PHENOMENOLOGICAL RESEARCH VOLUME CXVI

Founder and Editor-in-Chief:

A N N A - TERESA T Y M I E N I E C K A

The World Institute for Advanced Phenomenological Research and Learning

Hanover, New Hampshire, USA

Published under the auspices of

The World Institute for Advanced Phenomenological Research and Learning A-T. Tymieniecka, President

For further volumes:

http://www.springer.com/series/5621 
Anna-Teresa Tymieniecka

Editor

Phenomenology
of Space and Time

The Forces of the Cosmos and the

Ontopoietic Genesis of Life: Book One

第 Springer 


\title{
Human Soul, Body and Life Horizons
}

\author{
Maija Kūle
}

\begin{abstract}
Phenomenology of life develops an essential transformation of the positioning of life, human being, soul and life horizons. Human soul reflects the passions of the earth and of the skies. There are two directions characteristic for the soul - upward and downward. Life horizons are closely connected with life forms, styles of living. It has been described in rather different cultures including post-modern culture. This paper deals with A.-T. Tymieniecka's ideas about the New Enlightenment and critique of too narrow an explanation of human subjectivity and body and discusses the need for balance between soul's directions and decreasing of materialistic, consumerism life form, orientations to primitive feeling of the world and Cosmos.
\end{abstract}

\section{Concept "Soul" in Phenomenology}

Concept "soul" is difficult to explain because it is multi-meaningful. From ancient times in old Greek language soul means - psyche. But it does not mean that today when we are using the term "psyche" in the psychological sense - it is the same as the philosophical concept "psyche as soul". Soul is described as living essence or inner force of living beings, as the distinguishing feature of all living creatures, as the subject of emotional states, force that is responsible for acting, planning, doing. Brittanica online describes "soul" as the immaterial aspect or essence of human being. Soul can be explained as a bearer of moral qualities because ancient poets and philosophers spoke about courage souls, wet and dry souls, responsible souls, rightful souls and so on. The Italian philosopher Angela Ales Bello characterizes

M. Kūle (西)

Institute of Philosophy and Sociology, University of Latvia,

Akademijas laukums 1, Riga, Latvia

e-mail: maija.kule@gmail.com 
soul from the phenomenological point of view: "[..] phenomenological analyses tend to consider the soul not as a monolithic unit, but as a complex terrain of acts and operations that have also different qualities; some of these constitute the psyche, which has to be referred to everything that we find within ourselves by way of impulses, tendencies and spontaneous assumptions of position that cannot be eliminated, though they can eventually be controlled by a series of free and voluntary acts; since the latter enable us to take decisions, they have peculiar characteristics and therefore form part of a different sphere that is defined as spirit. The psychic and spiritual complex is different from corporeity (bodiliness) and, wanting to use a unitary term, can be called soul."1

There are different aspects how soul is characterized at the history of philosophy and culture:

1. As power of life, expression of being alive;

2. As core of sensations and psychological functions;

3. As form of body (Aristotle);

4. As immaterial substance which stays alive after subject's death, it differentiates body from corpse and represents an essence of living [human] being;

5. As God's implementation into the human's body;

6. As consciousness, reason; result of the combined action of the sensual and the spiritual force; soul is an intermediary between physical and the spiritual;

7. As person's essence, expressed by philosophical concept "me-ness";

8. As historical and cultural background for changing identity;

9. As poetical metaphor but not something real;

10. As phenomenon of imagination;

11. As empty concept, mistake of philosophy and theology.

Anna-Teresa Tymieniecka in the phenomenology of life recognizes that soul exists, it isn't an empty category but the concept which plays a very important role in the system Cosmos, Logos, human being. Body is animated by a psyche and enlivened by the spirit. Soul requires the body for its natural existence. An important step for the explanation of soul is attributing to it intellectual activities and ethical values. The philosophical idea of soul helps to unifies mind with body, cognitive with emotional; to see close relationships between perceptions, feelings, reflections, doings; it unifies theoretical thinking with practical doing; thinking with will and evaluation. Soul tends to include all the functions of human beings and represents human development on the basis of going upward, it means - to the higher values and self-development. Soul is associated with feelings like hate and love, joy and grief, shame and anger, honour and dishonour, it means - moral qualities and virtues. Soul stands between life and death, wrote Plato. The same idea we can see today when children are playing computer games - heroes have souls and possibilities to lose them, but today games give to players non-possible potentialities - many souls; never before people had an imagination that the number of their souls can depend on their artificial, playful wish.

\footnotetext{
${ }^{1}$ A. Ales Bello, "The Study of the Soul between Psychology and Phenomenology at Edith Stein", in Cultura. International Journal of Philosophy of Culture and Axiology, 8/2007, p. 107.
} 


\section{Phenomenology of Life: Three Movements of Soul}

Phenomenology of life is to develop the extended understanding of soul. Tymieniecka develops an essential transformation of the positioning of life, human being, soul and life horizons. The concept "soul" alongsite with the concepts "Logos", "unity-of-allthere-is-alive" and "creative act" are main concepts of Tymieniecka's life philosophy. For phenomenology of life is understandable: human soul belongs to the process of life development on the Earth and self-individualization of human persons. Human soul reflects the passions of the Earth and of the skies. It is not a narrow and subjective characteristic of human subjectivity but involves human beings in the large cosmic circle of creativity. Human existence in the orbit of life is the main problem at the phenomenology of life. She includes soul into the context of Cosmos and demonstrates development of rather different strata of souls as the creative development of the Universe under the expanding of the potentialities of Logos. Tymieniecka shows that the logos of life is an intelligent design of all things and intelligence itself, measure and proportion of all things, in itself - logic, insight, intuition, awareness, sentience. The Imaginatio Creatrix transforms the more primitive stirrings of the human soul into subliminal passions of human existential significance. "Imaginatio Creatrix proceeds from the womb of life and depends on it."

Tymieniecka describes three sense-bestowing functions of Imaginatio Creatrix:

(a) Aesthetic, poetic sense;

(b) Objectifying sense;

(c) Moral sense.

Moral sense is not the product of reasoning, but rather the result of subliminal passions that acquire their moral dimension guided by the benevolent sentiment.

Tymieniecka is interested in the lived soul, including its virtualities, its élan vital, soul's structure and unity of besouled human person. Kathleen Haney characterizes the specific understanding of soul in Tymieniecka's philosophy: "Tymieniecka's own examination of the life of the soul focuses on the affective dimension." 3 Affective dimension is expressed in the explanation of soul as power of life; as individualization of Logos; as core of sensations; as representation of human being in the Cosmos. In the book "Logos and Life: the three movements of the soul" Tymieniecka describes the extended phenomenology of soul characterizing the soul as the "soil" of lifeforces, as the subliminal "soil" of individualized life. Soul as person - it is meaning endowing complex. "This complex (which, in its manifestation we call the soul) is a germinal soil in which the play of the primeval life-forces within the life-schema

\footnotetext{
${ }^{2}$ A.-T. Tymieniecka, "Creative Imagination in the Converting of Life's Sensibilities into Full Human Experience" in Phenomenology of Life-from the Animal Soul to the Human Mind, Analecta Husserliana, Book 2, The Human Soul in the Creative Transformation of the Mind, vol. XCIV (Springer, 2007), p. XVII.

${ }^{3} \mathrm{~K}$. Haney, "The Three Movements of the Soul in Tymieniecka's Philosophy" in The Passions of the Soul in the Metamorphosis of Becoming. Islamic Philosophy and Occidental Phenomenology in Dialogue, vol. 1 (Kluwer Academic publishers, 2003), p. 49.
} 
enters, into generative context with the virtualities of Human condition." ${ }^{4}$ Olga Louchakova-Schwartz comments on her understanding of Tymieniecka's philosophy, that mental health is the ontopoietic functionality of the soul. Emergence of the soul creates a differentiation of Self and Other, realizes principle of unity-of-allthere-is-alive and principle of individualization. Soul allows human being to reflect about his or her trans-empirical experience, striving for the beautiful, truthful, just, infinite and the Absolute.

The theory of soul has been developed in the context of the New Enlightenment, it means new understanding of human being, his or her reason, unifying imagination and creative aspects. Reason therefore is inseparable from life process. New ontology for the phenomenology of life means unity of knowing and being. This understanding counteracts the post-modern loss of meaning. New Enlightenment emerges in the post-post-modern time, it involves networks of life; ontological self-poiesis of life, unification of reason and intuition. Tymieniecka recognizes that postmodern Self is endangered Self with disintegration of identity, based on self-fragmentation and disappearing of the unity of soul. She does not focus on self-fragmentation, for her central category is LIFE, not existence; but beingness as process and time; logic ontopoiesis, not time as structure which categorizes existence. For her life times itself; constitution of worlds and others is an opportunity for the creativity. Logos is directly intuited within a phenomenological horizon of life.

\section{Soul: Life and Death}

Sixteenth-century French essayist Michel de Montaigne wrote: "As we are born we die, and the end commences with the beginning. All the whole time you live, you purloin from life, and live at the expense of life itself. The perpetual work of your life is but to lay the foundation of death. You are in death, whilst you are in life, because you still are after death, when you are no more alive; or, if you had rather have it so, you are dead after life, but dying all the while you live; and death handles the dying much more rudely than the dead, and more sensibly and essentially. If you have made your profit of life, you have had enough of it; go your way satisfied."5 Recognizing the uniqueness of birth and death people have always been baffled by the body.

In contemporary Europe, however, there are but few who would consider death a part of life. People try to avoid the concept "soul". Artists, novelists, poets, priests and philosophers might form the exception.

Traditional Europeans admit dying of diseases and do not see the connection between soul, attitude to death and life. Thus, people blame doctors for death and

\footnotetext{
${ }^{4}$ A.-T. Tymieniecka, Logos and Life: the Three Movements of the Soul: the Spontaneous and the Creative in Man's Self-Interpretation-in-the-Sacred (Springer Verlag New York, 1988), p. 8.

${ }^{5}$ M. de Montaigne, Essays. Vol. 1, http://oll.libertyfund.org/simple.php?id=107\#chapter_20794 20794
} 
diseases and do not take them to be part of life and its final stage. Every achievement of medical science gives rise to a new variety of death, a new mutation. Death adapts and changes just like a virus. The moral philosopher Hans Jonas admits: "Death does no longer seem to be an innate necessity of live nature, but rather an erroneous organic creation that could be avoided - certainly to be discussed and depicted in detail." ${ }^{\prime 6}$ The connection between soul - as essence of living beings- and death in many post-modern cultures has been lost dramatically.

People usually avoid thinking about the grievous questions of life and death, or else they just believe religious doctrines. Life, death, evaluation of one's lifetime that are essentially philosophical and ethical problems in life are more and more often treated with soulless practicality, shameless greed and industrial functionalism. The reasons for it are to be sought in a distant past - when life started to be regarded as a sum total of separate parts and human being - mainly as a physiological mechanism and a social role player; when economy, finances and politics came to the fore in the social life of society. It does not mean that the New Enlightenment has come. The other way round - we can almost with certainty state that life is no longer sacred, belief in soul's existence has been lost, death does not inspire reverence and man's life can quite often find no satisfaction. Body, soul, spirit have lost unity. In the contemporary secular life form death does no longer mean the beginning of life after death or the meaningful summary of life, but an inability to plan something in the future. There is not a concept of soul. In value degradation conditions sufferings become more multiform and longstanding; increase egoistic, insensitive and indifferent attitudes towards the life of others.

Value degradation comes to light most clearly in the attitude towards the great mysteries of being - birth, life process and death. If death is not regarded to be a tragically sacred, unique event (if there is no thought that the death of every man is death of a whole world), but just statistics, an everyday occurrence, then in the morgue corpses can be mixed up and relatives handed out a stranger, as has already been the case in some developed states. Then victims of an accident can be calmly robbed because they are taken to be people just like all others, only they do not move and cannot slap the thief's hand. Idea of soul disappears.

It is strange, but for the majority of people views on death have simplified thus far that in their eyes death does not accord a different status - inviolability, eternity and liberation from any social roles or relationships. In Soviet socialistic countries it was fashionable to remove the burying places of the soldiers killed in World War II: the remains were dug out by excavators and then dropped in the earth again. Killed soldiers continued to play social roles after death and became part of ideologized parks. Nowadays there is also a wish to settle accounts with the dead people as if after the death they were continuing to perform their political and military mission. The social, political and military role outlives man. But the idea about human soul does not. That is the paradox of post-modern society.

\footnotetext{
${ }^{6}$ Hans Jonas, Das Prinzip Verantwortung, (Frankfurt am Main: Suhrkamp, 1984), S.48.
} 
Death has assumed the meaning of a socially practical, financial and medical phenomenon losing to a great extent the existential and life-completing sense. ${ }^{7}$ It is an unfortunate event, as it were, (one cannot exclude medical errors, of course), an unexpected moment (how could it, in principle, be unexpected if everybody knows the absolute truth that man is mortal?). People have lost feelings of the dialectics of life and death. Ancient and classical philosophers closely put together life and death based on the concept of soul. Today living is interpreted as self-sufficient phenomenon for long time because lifetime in the post-modern opinion depends on new projects in medicine and technologies which will stop aging.

In post-modern societies living life means that you repeatedly find yourself concentrating on unessential, separate events, a succession of obscure processes in which man's birth and death are not accorded a fundamental meaning. Death is connected with hospitals, medicines and body weakness but not with the life one has lived being ensouled.

Most people avoid and experience fear of those who are on the deathbed. The usual tactic is to send an old and ready-to-die man to a medical establishment for care and cure. In old age man is much more than in youth at the mercy of medical manipulations. Honour and praise to medicine undertaking to conquer death! However in its deeper sense it is unconquerable and demands its share of love. In modern Europe death comes to hospital wards, in loneliness, without the intimacy with children, without summing up one's life, without soul.

It is only the Christian church that still keeps valid an invitation to confession, the nearness of the priest, deference to death. In worldly life deference to death has been lost.

Why is death taboo in contemporary life? Nobody wants to speak or write about it, its image appears either in a commercial or a perverse form (as a mishap or a killer's victim). Love has lost its spiritual magic and also its tragic component. It is mostly reduced to sex as a technology of life or to entertainment. Medical technology produced pregnancy prevention means enable one to separate sex from the life continuation mission.

Contemporary philosophy is looking for an answer to the question why in the classical life form people could have deeper and more durable feelings (and also conflicts and contradictions). Now deep feelings and durable faithfulness arouse suspicions: how come man cannot comply with the style of the age, what is the reason for it - an illness, "an old-fashioned upbringing" or stupidity. Sympathy and help without recompense is usually regarded as an exceptional case and reasons are sought to understand what has made people act like that.

Death is being commercialized. Just think of the number of firms, offices, enterprises that gain profit from death! Selling places for burial is profitable and of late a still better business has appeared in European Union countries - selling small coffins, burial places and small monuments to pets. Death that is not profitable and does not give rise to a journalistic intrigue is of no interest.

${ }^{7}$ See: J. Dollimore, Death, Desire and Loss in Western Culture, (London and New York: Routledge, 2001). 
Commercialization of death and its direct submission to medicine raises apprehensions as to one-sidedness in the understanding of life. People's death becomes a commodity in modern industry. My country neighbour says: "Now you can earn more making coffins than making beds." And he is quite right.

Death is manipulated with, especially in respect to those who are inferior in power, significance and the ability to oppose. The interconnection between enlived soul and end of life has been lost in post-modern cultures. It has been reflected in many contemporary philosophical trends which do not reflect upon the concept "soul".

\section{Soul and Body: Life Horizons Upward and Downward}

The seventeenth-century French philosopher Blaise Pascal says: "Who would not think, seeing us compose all things of mind and body, but that this mixture would be quite intelligible to us? Yet it is the very thing we least understand. Man is to himself the most wonderful object in nature; for he cannot conceive what the body is, still less what the mind is, and least of all how a body should be united to a mind. This is the consummation of his difficulties, and yet it is his very being. Modus quo corporibus adhaerent spiritus comprehendi ab hominibus non potest, et hoc tamen homo est. ${ }^{8}$

Unity of material body and spirit has been analyzed as mind-body problem at the history of philosophy. It is one of the main problems in the cognitive sciences and philosophy of mind. History of philosophy demonstrates turn from the Cartesian dualism of body and mind. The turn has been directed to the recognition of ensouled body, as Maurice Merleau-Ponty recognizes, to the intentionality of body.

Man's being in a meaningful cultural world affords human dimensions to the sensational level. The body experiences sensations. The bodily sensations are grasped by the mind. People on the basis of their experience, upbringing and culture are able to evaluate the information the body provides. Sensations provide the roughest contact with the world; feelings are spiritually on a higher level reflecting life forms. Feelings can be refined, lasting or primitive, rash and transitory. MerleauPonty thinks of the body as "symbolism of the world". He writes: "My body is not one of what is grasped, it is the measure of all, the zero point of all the dimensions of the world." 9

Every one of us grasps the world based on one's own body as the centre. The body is an entity grasping all the other objects around him being in the "centre". The body as a centre of a reading system forms the parameters of perception "nearer", "further off", "up", "down", etc. Bodily sensations are at the basis of many world myths. Space from the point of view of human relations is grasped through the body.

\footnotetext{
${ }^{8}$ Blaise Pascal, Thoughts. No.72 http://etext.lib.virginia.edu/toc/modeng/public/PasThou.html ${ }^{9}$ Maurice Merleau-Ponty, The Visible and the Invisible (Evanston: Northwestern University Press, 1968), pp. 248-249.
} 
Thus, the body is the "point of vision" from which we look at the world. "My body is not an object, sooner I am my body." 10

The body is the basis for communication because it acts as a mediator in order to grasp another I. A caress of a loving hand sends a message to the other of the tenderness of their mutual relations; a blow conveys hatred. Another I we perceive in his bodily shape and ourselves in the flesh, so to say. Characteristically, I perceive my body very personally because my grasp is accompanied by my understanding of it. Another does not feel the pain in this or that part of the body the way I feel it. The body we grasp as an object cannot be my body - it seems impossible, as it were, if we wish to be human beings, not some degraded biological clots.

In the classical life form the body as flesh is the carrier of the spirit of another man, a mediator for understanding and cooperation to appear. In this sense the body cannot be grasped only as some sign.

In all life forms the human body has been an important entity included in the value hierarchy. In the life horizon upward the body is not at the top of the ladder because matter, decay, unconscious passions and desires weigh it down. Spirit is undoubtedly superior to the body because it rises upward to God. Since the time Europe accepted Plato's view of the world it has been divided into the sensuous and the trans-sensuous world. The trans-sensuous part is superior to the sensuous one because it can grasp the eternal and the imperishable. The body is born and dies; that is why in the Western classical culture the body is valued lower than the immortal soul.

In the classical age there are different ways of interpreting the relations between the body (flesh) and the soul, between the physical and the spiritual spheres. If superiority of the spiritual sphere is accentuated, the material body acquires the role of a lackey that is jokingly called "brother donkey". The flesh can be starved; its passions can be suppressed and exploited. Europe is familiar with different religious ways of controlling passions: asceticism implying complete refusal of all worldly goods, life in a convent by way of separation from the temporal world, a life of a hermit, piety - a spiritual trend that started in the seventeenth-century Lutheranism and denotes strict devoutness in everyday life.

The soul and the flesh are not separated from each other. Christianity teaches that the flesh influences the soul; it is carried away by passions, grief, anxieties and apprehensions. The soul may be sinful and it is not only the flesh that is at fault. In Augustine's opinion, a sinful soul spoils the flesh. That is why the soul should cling to the upper rank constantly purifying itself from sins and not submitting to the flesh. Even such an extremely active bodily sphere as sexual relations is devoted in the first place to the continuity of one's life in children, not to sensual enjoyment. In the life horizon upward it is clearly manifested in the restriction of passions, a drive for spiritual values, immortality. If the flesh strives upward, then it is redeemed flesh.

\footnotetext{
${ }^{10}$ Gabriel Marcel, The Mystery of Being, vol.1, trans. G.S. Fraser (Chicago: Henry Regnery, 1960), p. 123 .
} 
Some psychologists consider that the soul and the body are only theoretically separated because there is actually no such division. Carl Gustav Jung admits that he doubts whether this separation of the soul and the body is not only a way to investigate one and the same fact we effected division into two concepts illicitly affording them an independent existence. The English philosopher Bertrand Russell thinks that it is with Christianity that the tendency to separate spirit from matter is closely connected because Christianity tries to separate the soul from the body. Christianity is averse to the body as such. That is what influences the negative attitude towards the body in the life horizon upward.

With the change of life forms in no other sphere is there such a drastic overturn of hierarchy as in the relations of the body and the soul. In the post-modern secular age the word "soul" is to be found in the wastepaper basket of old-fashioned words. The words "spirit" and "spirituality" in many languages drag out a miserable existence reminding us of former Christian values. The English word "spirituality" occurs mainly in religious contexts while the German "Geist" is not a politically correct word if people remember its role in the Nazi ideology.

In the post-modern age the body is grasped in its meaningful liveliness and the spiritual sphere - in a much closer affinity with the body. In the contemporary life form it is not the soul that tries to save the body, but the flesh embodies the soul. The body is ascribed everything that is valuable that was formerly ascribed to the soul. The body lays claims, raves, enjoys and puts on masks. The body thirsts for immortality, but now it is promised as a life prolongation programme as far as technology and pharmacology are able to insure. If at the beginning of the twentieth century bodily challenges were regarded to be an attestation of liberation, then in the contemporary life forms emancipation of the flesh is over. Twenty-first-century post-modern culture demonstrates games with body without soul, not human liberation.

In the life horizon upward feelings are regarded to belong to a lower rank. Understanding and the mind are above sensations. Sensations supply the material the mind processes. The life form characteristic for post-modern people turns it upside down: sensations can express feelings. Feelings are reduced to the level of sensations, the higher - to lower. Life horizon turns downward.

In the classical culture the merger of feelings with sensations is inadmissible. Taste does not give rise to feelings because the lower is in no way able to create the higher. A fine taste for coffee can change your mood for the better, but it will not directly affect your spiritual feelings, your soul. Classical culture takes care of developing feelings, looks for grasping the world in a spiritually refined way, soul tends to go upward, to spirituality, in German philosopher Max Scheler's words, to the fourth strata of feelings.

In the post-modern age the refined cultural layer that decreed inadmissibility of subjecting feelings to senses is shrinking. The American philosopher Robert Solomon analyzing the understanding of emotions nowadays admits that there is mythology and ideology of emotions. ${ }^{11}$ Emotions develop man's self-understanding

\footnotetext{
${ }^{11}$ Robert C. Solomon, The Passions. Emotions and the Meaning of Life (Indianapolis: Hackett Publishing company, 1993), pp. 21-23.
} 
and determine his relations with others, in some sense it is ideology of interpreting of "soul". The emotions that form our world create ideology - desires, hopes, demands, expectations that have to be satisfied. Mythology of emotions is an unconscious orientation; it turns into ideology of emotions when man starts clearly and definitely submitting to emotions; lives, acts and evaluates events under their impact.

Characteristically, in the post-modern life form there arise all kinds of emotionbased ideologies that are not formed as a result of refined upbringing, but aiming at satisfying one's bodily requirements. It isn't spiritually ensouled body but functional body. One of those is that sexual needs are at the centre of man's life. Sex is spoken of as a totality of technologies, a source of sensations of pleasure and physical energy. Emotions accompanying sex are the simplest ones - lust, desire to subject and use.

Another emotional ideology of today refers to glamorized appetite or gastronomy. In affluent countries with no hunger problems a cult of eating with gusto has sprung up. An enormous number of cookery books leave in the shade all the other types of literature. Delicacies, finesse and originality in garnishing - all to please your eye and thrill your palate when you relax in delight after an aesthetically prepared meal. Wine experts in the eyes of society are more eminent than poets who write about souls, for instance. Gastronomy even manages to become poetic and "ensouled". Eating a lot and making love without measure, man satisfies his or her elementary needs, but he or she does not grow in eminence. At times exactly the opposite is the case - emotions evoke degrading sensations and diseases. Overdrawn elemental bodily feelings lead to collapse of personality, neurosis, obtuseness, excessive infatuation with the eating cult leads to vegetative diseases and an aversion to food.

Man's freedom is turned into perverse freedom. Man's activity is limited by his or her unwillingness not by impossibility or inaccessibility. However unwillingness is not given naturally, it has to be cultivated. The human body freed from the control of the spirit desires every moment of gratifying his physiological urges. To stop the triumphant march of the body one needs a different value system from the one prevailing in the life horizon downward to lowest feelings. However, the classical feelings of duty, abstinence and spirituality are unfortunately moved aside as outmoded.

The body is like a sign on which the consumer culture inscribes its codes. Soul has been lost or enlivened by marketing. Human spirit has been changed into social role and trends. Personality has been broken into parts, ideas of permanently changed identity have been developed in social sciences. No recognition of soul as a core of human historical transitions. Unity of body, soul and spirit becomes only illusion. Peter Sloterdijk tells when the famous French prostitute Arletty was accused of having had sexual relations with members of German occupation forces, her answer is said to have been: "My heart is French, but my backside is international." 12 Her rude but apt answer is typical of a person who feels divided, as it were, in spirit and body, it means to be a broken post-modern personality.

${ }^{12}$ Peter Sloterdijk, Critique of the Cynical Reason (Minneapolis: University of Minnesota Press, 1987), p. 148. 
However, body is not as capable as the mind, it is unable to grasp interconnections, it is unable to reflect. Paradoxically, but the organs of senses can perceive objects affecting them, but they cannot perceive their own selves. Sight can see things, but it cannot see seeing. The organs of sense lack something that is inherent in the mind, namely, reflection. That is why sensations cannot create anything higher feelings. Sensations cannot replace soul. The contemporary post-modern life form exaggerating the experience of senses reduces human being to a lower level of existence in comparison with the life form upward that anticipates feelings that are not connected with one's body (the feelings of sanctity, for instance).

The Body Art Movement coined the slogan - truth belongs to those who experience physical pain. It does not mean redemption. That spells an essential difference from the standpoints of the classical age. In the classical standpoint truth is connected with sufferings that can raise human being to a higher spiritual level, soul strives upward - to God.

In the post-modern standpoint the aspiration upward does not exist, sensations are used only as one of the many designators. It evokes shock, fear and a sense of emptiness in the audience. Post-modern artist Gina Pane thinks that alongside her performances "physical suffering is no longer a personal problem; it becomes a language problem. The body itself becomes an idea while formerly it was nothing else but a way to transfer of ideas." ${ }^{13}$ However, on the other hand, the body does not become an idea, but a thing of no higher value than other things.

Turning the body into a thing is something contemporary philosophers have been warning against. Thus, even blood loses its carnality, its corporeality and turns into a threat, a sign of disease or viewed from another stance - into a manifestation of endangered sexuality, not into the basis of life.

At present attested are not corporeal values, but sooner lack of their value. The diseased as such is a fact in our view, but the idea of his and every one's including our own immortality, finality and vulnerability is generated in us, the living ones.

Changing the body into a thing tends to get closer and closer to the body which is not ensouled body. Consumer society gathers speed to cultivate sensations and trivialize feelings. Getting the world of things man lost soul. Pascal writes: "The victory over death". "What is a man advantaged if he gain the whole world and lose his own soul? Whosoever will save his soul, shall lose it." ${ }^{\prime 4}$

Phenomenology of life emphasizes the need for balance between soul's directions and decreasing of materialistic, consumerism life form, orientation to primitive feeling of the world and Cosmos. Phenomenology of life is right that postmodern Self is endangered Self, it is characterized by disintegration, broken identity, based on self-fragmentation and disappearing of the unity of soul. Restoring of harmony between human body, soul and spirit is the fundamental basis for developing of contemporary culture.

\footnotetext{
${ }^{13}$ Francesca Alfano Miglietti, Extreme Bodies. The Use and Abuse of the Body in Art. (Milan: Skira editore, 2003), p. 28.

${ }^{14}$ Blaise Pascal, Thoughts. No.782. http://etext.lib.virginia.edu/toc/modeng/public/PasThou.html
} 